\title{
EMPREGO DA EXSANGÜINEOTRANSFUSÃO EM ACIDENTE LOXOSCÉLICO HUMANO, GRAVE
}

\author{
Marcos Vinicius da SILVA (1); Milton Roberto T. CRENITTE (2), Vera Lúcia FURST (3) \&
}

Paulo Antonio LeITÃo (4)

\section{R E S U M O}

Foi utilizada a exsangüineotransfusão, associada à soroterapia heteróloga específica e alcalinizaçāo urinária, em um caso de acidente loxoscélico humano na cidade de Sâo Paulo. A indicação da exsangüineotransfusão foi a intensa hemólise associada à gravidade e o iminente risco de morte.

UNITERMOS: Acidente aracnídico; Loxoscelismo; Exsangüineotransfusão.

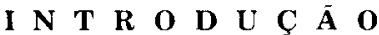

Os acidentes humanos causados por animais peçonhentos são freqüentes no Brasil. Nos atribuídos as aranhas tem grande importância os determinados pelo gênero Loxosceles ${ }^{20}$.

Sāo aranhas de hábito noturno, vivem em lugares escuros, pouco agressivas, medem de 16 a $30 \mathrm{~mm}$, de cor marrom, o que lhe confere o nome popular de "aranha marrom", 18 seu veneno uma vez inoculado no homem, acarreta uma série de alterações patológicas, atribuidas à natureza enzimática, como a necrose local e a hemó lise l. $^{85}$.

No momento da picada nāo ocorre dor local, na maioria dos casos. Esta aparece após $15 \mathrm{minu}$ tos a 8 horas e acentua-se com o passar do tempo, podendo ser acompanhada de prurido, edema, eritema e "clareamento" da área picada, que posteriormente adquire cor violácea a partir do ponto de inoculação. Em sua progressão pode apresentar manifestaçōes gerais e locais, como: vesícula e/ou bolha, necrose de toda à área, evo luindo com mumificaçāo da área central e formaçāo de escara que ao destacar-se deixa uma ulceração. Estas manifestaçóes caracterizam a for ma cutânea destes acidentes ${ }^{4.16}$.

Outra forma é a víscero-cutânea, bem mais rara e mais grave, além das manifestações apre sentadas na forma cutânea, é acompanhada de hemólise intravascular, distúrbios da coagulaçāo sangüinea, hemoglobinúria, proteinúria, oli gúria, anúria, insuficiência renal aguda, hiperbi lirrubinemia e icterícia. Podendo levar o pacien te à morte, principalmente quando a assistência médica é procurada tardiamente. Há também relato de mielite transversa com paralisia ${ }^{3 .}$. 19

(1) Médico do Hospital Emilio Ribas e do Instituto Adolfo Lutz, ambos da Secretaria de Saúde do Estado de Sáo Paulo. Av. Dr. Arnaldo, $35510^{\circ}$ andar - Seção de Sorologia. Caixa Postal 7027. CEP 01246. Sào Paulo, SP., Brasil.

(2) Médico pediatra das Secretarias de Saude do Estado e Higiene do Municipio de Sảo Paulo. Sào Paulo, S.P., Brasil.

(3) Diretora Técnica da Fundação de Saúde do Município de Osasco (FUSAM). Médica. Osasco, S.P., Brasil.

(4) Medico do Hospital Emilio Ribas e Hospital Vital Brazil do Instituto Butantan. ambos da Secretaria de Saude do Estado de Sào Paulo. Sào Paulo, S.P., Brasil 
SILVA, M. V. da; CRENITTE, M. R. T.; FURST, V. L. \& LEITȦO, P. A. - Emprego da exsangüineotransfusão em acidente loxoscélico humano, grave. Rev. Inst. Med. trop. Sáo Paulo, 30 (4): 259-263, 1988.

\section{MATERIAL E MÉTODOS}

Relato de Caso: paciente do sexo masculino, 1 ano e 5 meses de idade, brarico, residente no bairro de Pirituba (regiāo metropolitana de Sāo Paulo), atendido em serviço médico no dia 5 de setembro de 1983 , por apresentar anorexia, febre $\left(38^{\circ} \mathrm{C}\right)$, hematúria e icterícia há um dia. Ao exame físico tratava-se de paciente eutrófico, em regular estado geral, prostrado, hidratado, descorado, ictérico $+2 /+4$, intensa hiperemia conjun. tival, petéquias na regiāo dorsal; hepatomegalia (fígado a $3,5 \mathrm{~cm}$ do rebordo costal direito).

Na região supra clavicular esquerda foi observada a presença de lesão endurada de limites precisos, bordos hiperemiados e endurados, de $\pm 1 \mathrm{~cm}$ de diâmetro, que a māe refere ter aparecido um dia antes do início da sintomatologia.

Após a internaçāo houve piora do estado ge ral, torpor, toxemia e aumento da ictericia; a urina que no início do quadro era de cor vermelha tornou-se preta. A lesāo na região supra cla vicular aumentou de diâmetro e adquiriu cor violácea, com centro necrótico, circundada por halo eritematoso, de bordos elevados; as petéquias na regiāo dorsal evoluíram para sufusōes hemorrágicas.

O paciente foi tratado em unidade de terapia intensiva devido a gravidade do caso, sendo instituído como terapêtica: soro antiaracnídico (Instituto Butantan), na dose de $50 \mathrm{ml}$ (10 ampolas), por via subcutânea no dia 6 de setembro, sendo que $1 \mathrm{ml}$ de soro neutraliza 15 doses míni mas necrotizantes de veneno de Loxosceles sp; hiperhidratação e medidas de suporte. Houve piora do quadro, sendo ministrado hidrocortisona $(40 \mathrm{mg} / \mathrm{Kg} /$ dia $)$, cimetidina $(0,5 \mathrm{mg}$ de $6 / 6$ horas), soluçāo de bicarbonato de sódio a $10 \%$ ( $3 \mathrm{mEq} / \mathrm{Kg} /$ dia) com a finalidade de alcalinizar a urina, gluconato de çálcio a $10 \%(20 \mathrm{ml} \mathrm{em}$ 24 horas $)^{11.12 .13}$. Nessa ocasião foram indicadas e realizadas quatro exsangüineotransfusôes com sangue citratado, em intervalos de 12 horas, to das as quatro com troca de duas volemias. Após as exsangüineotransfusôes foram ministrados mais $35 \mathrm{ml}$ ( 7 ampolas) de soro antiaracnídico (Instituto Butantan), para maior segurança, pois durante as exsangüineotransfusōes ocorreu remoçāo de parte do soro ministrado anteriormente e uma pequena quantidade de veneno ativo eventualmente poderia ainda ser neutralizado.

\section{RESULTADOS}

Após a primeira exsangüineotransfusão o paciente apresentou sinais clínicos de melhora, piorando após 4 horas com torpor, oligúria e he moglobinúria. Melhora clínica evidente e progressiva ocorreu após a segunda exsangüineotransfusāo, com melhora do nível de consciência, da toxemia, da icterícia e da hemoglobinúria, aumento do volume urinário e clareamento progressivo da urina até o normal.

A lesão supra clavicular apresentou involuçāo, e no momento da alta hospitalar (24? dia de internação), apresentava-se com ponto necró tico central, circundado por uma área eritematosa de bordos elevados. Recebeu alta para o domicílio, em bom estado geral.

Exames laboratoriais realizados: Tabelas n:s $1,2,3$ e 4 .

TABELA 1

Resultado de Hemograma

\begin{tabular}{|c|c|c|c|c|c|c|}
\hline Data 1983 & $5 / 09$ & $6 / 09^{* *}$ & $8 / 09$ & $11 / 09$ & $19 / 09$ & Valores normais para a idade \\
\hline Hemácias & 3.000 .000 & 2.000 .000 & 3.800 .000 & 3.600 .000 & 4.000 .000 & $3,8-5.2 \times 10^{6} / \mathrm{mm}^{3}$ \\
\hline Hemoglobina & 8.3 & 6,7 & 10,2 & 10,5 & 9,6 & $10,3-13,5 \mathrm{~g} \%$ \\
\hline Hematócrito & 17 & 16 & 34 & 31 & 32 & $32-40 \%$ \\
\hline Plaquetas & 80.000 & 163.000 & 76.000 & 220.000 & - & $2-4 \times 10^{5 / \mathrm{mm}^{3}}$ \\
\hline Leucócitos & 13.000 & 14.200 & 6.700 & 8.600 & 8.300 & $5-10 \times 10^{3 / \mathrm{mm}^{3}}$ \\
\hline Bastonetes & 40 & 30 & 20 & 06 & 01 & $1-4 \%$ \\
\hline Segmentados & 35 & 44 & 41 & 35 & 32 & $27-54 \%$ \\
\hline Eosinófilos & 03 & 08 & 02 & 00 & 04 & $1-3 \%$ \\
\hline Basófilos & 00 & 01 & 00 & 00 & 00 & $0-1 \%$ \\
\hline Linfócitos & 20 & 13 & 34 & 55 & 56 & $32-55 \%$ \\
\hline Monócitos & 02 & 04 & 03 & 04 & 07 & $2-7 \%$ \\
\hline
\end{tabular}

* Wintrobre modificado e BAAR modificado

** Início das exsangüineotransfusōes 
SILVA, M. V. da: CRENITTE, M. R. T: FURST, V. L. \& LEITÁO, P. A. - Emprego da exsanguineotransfusáo em acidente loxoscélico humano, grave. Rev. Inst. Med. trop. São Paulo, 30 (4): 259263.1988.

TABELA 2

Dosagem sangüinea

\begin{tabular}{|c|c|c|c|c|c|c|c|}
\hline Data 1983 & 609 & 709 & 909 & 1109 & 1409 & 19.09 & Valores normais \\
\hline Sódio & $\because$ & $\approx$ & 133 & 138 & $\ldots . .$. & 136 & $135-144 \mathrm{mEq}$ \\
\hline Potássio & $*$ & $\dot{s}$ & 3.2 & 4,4 & - & 4.1 & $3.6-5 \mathrm{mEq}$ \\
\hline Uréia & 113 & 100 & 98 & 82 & 115 & 69 & $15 \ldots-45 \mathrm{mg}^{\prime}$ \\
\hline Creatinina & 1,35 & 1,40 & 1.80 & 1.35 & 1.40 & 0.80 & $0.6-1.2 \mathrm{mg}^{\prime}$ \\
\hline
\end{tabular}

Impossivel a determinaça devido à hemólise

Obs.: metodologia utilizada: sódio - método fotómetro de chama potássio - método fotómetro de chama uréia - método Fearon (diacetilmonoxina) creatinina - método Jaffe modificado

TABELA 3

Exames Complementares

\begin{tabular}{|c|c|c|c|c|c|}
\hline Data 1983 & 509 & 609 & 809 & 909 & Valores normais \\
\hline Tempo de protrombina $\langle\mathrm{TP}\rangle$ & 18 & 16 & 13.5 & 12 & 12 segundos \\
\hline Atividade de protrombina (AP) & 37 & 50 & 80 & 100 & $100 \%$ \\
\hline Tempo de tromboplastina parcial (TTP) & 28 & 36 & 36 & 26 & $30-45$ segundos \\
\hline Fibrinogenio & 460 & 460 & 260 & 390 & $200-400 \mathrm{mg}$ \\
\hline Teste de Coombs direto & - & - & negativo & - & - \\
\hline
\end{tabular}

Obs.: Metodologia utilizada: tempo e atividade de protrombina - método de Quick tempo de tromboplastina parcial - método Bell Alton (cefalina ativada) fibrinogênio - método gravimétrico (Costa Ferreira)

TABELA 4

Urina Tipo I

\begin{tabular}{|c|c|c|c|c|c|c|c|}
\hline Data 1983 & $5: 09$ & 609 & 909 & 1309 & 1609 & 1909 & Valores normais \\
\hline Densidade & 1.034 & $\because$ & 1.010 & 1.005 & 1.005 & 1.015 & $1.015-1.025$ \\
\hline Proteina & 33.5 & 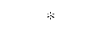 & 0.05 & 0,55 & 0,25 & 0.20 & ausente g 1 \\
\hline Cor & hemorrágico & $*$ & - & - & - & - & amarelo ámbar \\
\hline Células & 5.000 & 5.000 & 4.000 & 3.000 & 5.000 & 3.000 & ate $10.000 \mathrm{~mm}^{3}$ \\
\hline Leucócitos & 1.000 & 11.000 & 3.000 & 8.000 & 56.000 & 73.000 & até $10.000 \mathrm{~mm}^{3}$ \\
\hline Hemacias & 5.000 .000 & 200.000 & 21.000 & 37.000 & 6.000 & 9.000 & ate $1.500 \mathrm{~mm}^{3}$ \\
\hline $\mathrm{ph}$ & - & - & 7 & 6 & 6 & 6.5 & $5-6.5$ \\
\hline
\end{tabular}

nāo determinado devido à presença de hemoglobina.

\section{DISCUSSĀO}

O quadro clínico do loxoscelismo é bastante característico e o diagnóstico é clínico.

Estảelecido o diagnóstico de acidente arac nídico (loxoscelismo) os pais do paciente foram comunicados. A māe nos informou neste momento que um dia antes do aparecimento da lesão cutânea, havia encontrado na cama do paciente uma aranha morta, de aproximadamente
$1,5 \mathrm{~cm}$, de cor marrom e que só neste momento correlacionou os fatos.

Dos resultados dos exames laboratoriais al terados, como a discreta leucocitose e aumento de neutrófilos pode ser atribuido à resposta náo especifica ao veneno da Loxosceles ${ }^{21}$.

A severa anemia foi decorrente da hemólise ocasionada pela açāo do veneno. Existem várias teorias na tentativa de uma explicação e entre 


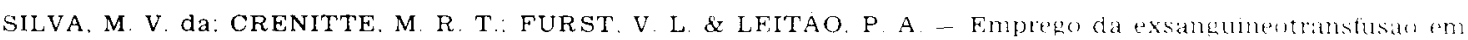
acidente loxoscélico humano, grave. Rev. Inst. Med. trop. Sìo Paulo, 30 (4): 259263.1988.

as mais aceitas estâo: a da fixaçáo do veneno em receptores de superficie da membrana dos eritrócitos e subsequente hemólise intravascu lar: a da hemólise por ativaçāo do complemento e ainda a da participaçào enzimática laçào da esfingomielinase tipo D hidrolisando componen tes da esfingomielina da superficie dos eritró citos, determinando hemólise $)^{7.4 .9 .419 .}$ it

O achado de púrpura, sufusỏes hemorrági. cas associadas à: trombocitopenia, aumento no tempo e diminuiçāo na atividade da protrom. bina, tempo de tromboplastina parcial diminui do, poderia sugerir uma coagulaça in travascu lar. o que pode ocorrer neste tipo de acidente ${ }^{2}$, embora nảo possamos fazer tal interpretaça pois nảo houve consumo de fibrinogènio, e nāo nos foi possivel nova mensuraçáo após o total restabelecimento do paciente para confirmaçảo dos seus reais valores.

Outro fato importante que cabe aqui ressaltar. e já citado na literatura ${ }^{21}$ é a nảo correlaçāo entre reaçóes sistêmicas e à intensidade dos fe. nòmenos locais

A alcalinização urinária foi instituída com o intuito de diminuir a deposição de metahemo. globina nos túbulos renais que ocorre mais facil mente em $\mathrm{pH}$ ácido.

A hemolise maciça, a gravidade do caso e a iminencia de morte, levou à instituiça da ex sangüineotransfusão com o objetivo de remover produtos resultantes da hemólise e catabólitos. melhorar a perfusảo capilar e prevenir a compli caçào mais grave desta forma que é a insuficièn. cia renal aguda, agravada pela deposiçāo de me tahemoglobina nos túbulos renais.

Atribuimos à exsangüineotransfusào grande parte do êxito conseguido, pois em nenhum momento foram observados sinais clinicos e ou laboratoriais de insuficiencia renal aguda. A me lhora significativa do paciente constatada após as exsangüineotransfusōes também é fato im portante

A exsangüineotransfusāo deve ser encarada como recurso possivel na prevenção das compli caçoes do acidente loxoscélico tais como a coagulopatia de consumo e a insuficiencia renal aguda. Tem sido realizada em pediatria. com su- cesso variável, dependendo da patologia de base a que se destina. A principal indicacáo da exsan guineotransfusảo é a retirada de elementos noci vos presentes na circulaça. As principais indi caçoes deste procedimento náo incluem o aci

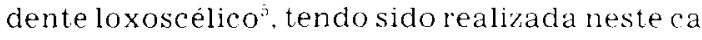
so, frente a gravidade e o iminente risco de mor te. como medida extrema que surtiu bons resul tados

Acreditamos que a associaçào da sorotera pia especifica, exsangüineotransfusáo alcalini zaçào da urina foram os fatores fundamentais para à sobrevivència deste paciente.

\section{SUMMAR Y}

\section{Utilization of exchange transfusion procedure in serious human loxoscelism.}

A case of human loxoscelism occurred in Sào Paulo City was submitted to exchange transfu sion procedure associated with specific hetero logous serotherapy and urinary alkalization. The exchange transfusion procedure was propo sed to be employed in this case, because of inten sive haemolysis associated with severity and im minent death risk

REFERENCIAS BIBLIOGRAFICAS

1. BASCUR, L.: YEVENES. I \& BARJA. P. Effects of Loxosceles laeta spider venom on blood coagulation. Toxicon, 20:795 796,1982

2. BERGER R S A ADELSTEIN E H \& ANDERSON, P C. - Intravascular coagulation: The rause of necrotic arachnidism. J. invest. Derm., 61: 142150,1973

3. BUTZ,W. C. - Envenomation by the brown re'cluse spide' Aranae, Scytodidae and related speries. A public halth problem in the United States Clin. Toxicol. 4: 515524 1971

4. FARDON. D. W.: WINGO C. W. ROBINSON L W \& MASTERS. F. W. - The treatment of bruwn spider bite Plast. reconstr. Surg., 40: 482488.1967

5. FIGUERDA. R \& FERNANDEZ. D - El rerambio de sangre en los infeceiones graves del recien nascido. Rev. Chil. Pediat., 50: 75 77, 1979

6. FOIL. L. D. \& NORMENT, B. R. - Envenomation by Lo. xosceles reclusa. J. med. Entomol., 16:18.25. 1979

7. FORRESTER, L. J.: BARRETT, J. T. \& CAMPBELL. B J. - Red blood cell lysis induces by the venom of the brown reclusa spider. A rch. Biochem., 187: $355365,1978$. 
SILVA, M. V. da: CRENITTE, M. R. T.: FURST. V. L. \& LEITAO. P. A. - Emprego da exsanguineotransfusào pm acidente loxoscélico humano, grave. Rev. Inst. Med. trop. Säo Paulo. 30 (4): 259263.1988.

8. FORRESTER. L. J.: CAMPBELL. B. J. \& BARRETT. J. T. - Sphingomyelinase $D$ from brown recluse spider ve nom. Toxicon, 25: 141.1987

9. FUTRELL J M : MORGAN B B \& MORGAN P N - An in vitro model for studying homolysis associated with venom from the brown recluse spider (Loxosceles reclusa). Toxicon, 17: 355-362, 1979

10. KELEN, E. M. A.: ROSENFELD. G. \& NUDEL, F. - Hemolytic activity of animal venoms. II Variation in relation to erythrocyte species. Mem. Inst. Butantan, 30: 133.142 . $1960 / 62$

11. KOPELMAN, B. I: MIYASAKI. C. H.: GOMES. C. E. T \& RIBEIRO, A.J.M. - Rendimento da exsangumentrans fusào. Pedit. prat. (S.Pauto), 50(1 2): 1516.1979

12. KOPELMAN B 1 MIYASAKI C H : GOMES ( $\mathrm{F}$ : \& RIBEIRO, A. J. M. - Alteraçōes de glicemia, sodio, po tássio e calcio durante a exsanguneotransfusào. Pediat. prát. ( S.Paulo), 50(1-2): $12-14,1979$

13. KOPELMAN. B. I.: MIYASAKI, C. H.: GOMES. C. E. T \& RIBEIRO, A. J. M. - Alteraçoes do pH, $\mathrm{pCO}_{2}, \mathrm{pO}_{2}$ $\mathrm{HCO}_{3}$ durante e após a exsanguineotransfusâo com san gue em soluçāo ACD. Pediat. prát. (S. Paulo), 50(4-6): 61 -64 1979.

14. MORGAN, B. B.; MORGAN, P. N. \& BOWLING, R. E - Lysis of human erythrocyts by venom from the brown recluse spider, Loxosceles reclusa. Toxicon, 16: 85-88, 1978 .
15. ROSENFELD. G.- Molestias por venenos animais Pi. nheir. ter., 17 (84): 3 15. 1965.

16. ROSENFELD G: NAHAS L : De CILLO D M \& FLEU RY, C. T. - Envenenamentos por aranhas, serpentes $e$ escorpiōes. In: PRADO, C. F.; RAMOS, J. \& RIBEIRO DO VALE, J. - Atualizaçáo terapéutica. Sào Paulo. Artes Médicas, 1978. p 10201037

17. SCHENONE. H. \& PRATS. F. - Arachnidism by Loxosceles laeta. Arch. Derm., 83: 193196.1961

18. SCHENONE. H. \& LETONJA, T. - Notas sobre la biologia y distribucion geográfica de las aranas del género Loxosceles. Bol. chil. Parasit., 30: 27 29, 1975.

19. SMITH. C. W. \& MICKS. D. W. - Comparative study of the venom and other components of three species of Lo. xosceles. Amer. J. trop. Med. Hyg., 17: 651-656, 1968

20. TORRES, J. B. \& CARLOTTO, P. R. - Levantamento dos gêneros de ofídios e espécies de aracnídeos causadores de acidentes na casuistica do Centro de Informaçoes Toxi cologicas do Rio Grande do Sul. Mem. Inst. Butantan, 46: $207-218,1982$

21. WASSERMAN, G.S. \& SIEGEL, C. - Loxoscelism (brown recluse spider bites): a review of the literature. Clin. Toxicol., 14: $353-358,1979$

Recebido para publicaçāo em 23/09/1987 